\title{
AGROBIODIVERSIDADE NAS COMUNIDADES GUARANI- NHANDEWA NO NORTE DO PARANÁ: MEMÓRIA E RESGATE
}

\author{
THIAGO VALENTE VIEIRA DE ALMEIDA ${ }^{1}$
}

UFSCAr

MARCIANO RODRIGUES ${ }^{2}$

ARPIN-Sul

LUIZ ANTONIO C. NORDER ${ }^{3}$

UFSCar

\begin{abstract}
RESUMO: O manejo das variedades tradicionais de sementes entre os povos indígenas tem recebido atenção crescente nos últimos anos. Esta pesquisa analisou a agrobiodiversidade na Terra Indígena Laranjinha, habitada por índios Guarani-Nhandewa, na região Norte do Paraná. $O$ estudo analisou aspectos da memória local sobre as diversas sementes indígenas, suas características e usos, bem como as práticas agrícolas empregadas. Foram ainda registradas as intenções dos indígenas em resgatar esta agrobiodiversidade e as principais dificuldades encontradas. A pesquisa mostra que as Feiras de Trocas de Sementes Crioulas e Tradicionais Indígenas, realizadas anualmente desde 2011, na Terra Indigena Pinhalzinho, também no Norte do Paraná, representam uma nova estratégia coletiva para o resgate e revalorização da agrobiodiversidade, pois organizam esforços até então pontuais e difusos para a localização e produção de variedades de arroz, feijão, batata doce, mandioca, milho e outros alimentos. $O$ resgate da agrobiodiversidade fortalece a identidade cultural e contribui para a reconstrução da organização comunitária.
\end{abstract}

PALAVRAS-CHAVE: Guarani-Nhandewa; Agricultura Indígena; Agrobiodiversidade.

ABSTRACT: The management of traditional varieties of seeds among indigenous communities have been receiving increasing attention for the past years. This research examined agrobiodiversity in the Laranjinha Indigenous Land, in northern Paraná State, inhabited by the Guarani-Nhandewa people. The study analyzes the local memory about the various indigenous seeds, their characteristics and uses, as well as agricultural practices. We also verified their intention to recover agrobiodiversity practices and major difficulties to do so. The Feiras de Trocas de Sementes Crioulas e Tradicionais Indígenas (Traditional and Indigenous Seeds

\footnotetext{
1 Bacharel em Ciências Biológicas pela Universidade Estadual Paulista "Júlio de Mesquita Filho" (UNESP), Câmpus Experimental do Litoral Paulista, Polo São Vicente. Mestre em Agroecologia e Desenvolvimento Rural pela Universidade Federal de São Carlos (PPGADR/UFSCar). E-mail: valente.macu@gmail.com .

${ }^{2}$ Guarani-Nhandewa da Terra Indígena Laranjinha, Secretário Institucional da Articulação dos Povos Indígenas da Região Sul (ARPIN-SUL). E-mail: referenciaindigena@yahoo.com.br .

${ }^{3}$ Professor do Programa de Pós-Graduação em Agroecologia e Desenvolvimento Rural da Universidade Federal de São Carlos (PPGADR/UFSCar). E-mail: luiz.norder@cca.ufscar.br .
}

Espaço Ameríndio, Porto Alegre, v. 8, n. 1, p. 40-58, jan.jun. 2014. 
ALMEIDA, RODRIGUES e NORDER - Agrobiodiversidade nas comunidades guarani...

Exchange Fairs), held yearly since 2011 in the Pinhalzinho Indigenous Land, also in northern Paraná, is a new collective strategy for recovering biodiversity, for it reorganizes efforts (individual until then) in finding seeds and producing traditional varieties of rice, beans, sweet potatoes, cassava, maize, and other foods. Revaluation of agrobiodiversity fortifies cultural identity and contributes to rebuild the collective organization.

KEYWORDS: Guarani-Nhandewa; Indigenous Agriculture; Agrobiodiversity.

\section{Introdução}

Nos últimos anos, vem se ampliando o debate público sobre a erosão da agrobiodiversidade e sobre sua relação com aspectos culturais em populações camponesas, indígenas e tradicionais (SANTILLI, 2009). A intensa concentração econômica gerada pelos conglomerados agroindustriais vem tornando camponeses e populações tradicionais crescentemente dependentes do fornecimento de insumos, produtos, conhecimentos e sistemas de comercialização (PLOEG, 2009). Neste processo de globalização e padronização da agricultura, muitas variedades de plantas melhoradas através de práticas comunitárias tradicionais vêm sendo abandonadas e substituídas por cultivares desenvolvidos e comercializados por grandes empresas do setor.

A intenção de manter e incrementar as diversas formas de vida que compõem o ecossistema agrícola resultam em práticas que favorecem a agrobiodiversidade, que pode ser definida, resumidamente, como a parcela da biodiversidade utilizada na agricultura e na criação animal de forma domesticada ou semidomesticada, de acordo com a Convenção sobre Diversidade Biológica, realizada durante a Conferência das Nações Unidas para o Meio Ambiente e Desenvolvimento Sustentável - Rio92 e, posteriormente, ratificada por 168 países.

As políticas voltadas para a valorização da agrobiodiversidade estão cada vez mais em pauta nas discussões e tratados internacionais. No Brasil, a Lei de Proteção de Cultivares (Lei 9.456/97) e a Lei de Sementes e Mudas (Lei 10.711/03) têm como objetivo incentivar camponeses e populações tradicionais para a produção de suas próprias sementes de variedades locais, chamadas também de crioulas. A Lei de Sementes e Mudas, em seu Art. 8o, § 3o, determina que: 
ALMEIDA, RODRIGUES e NORDER - Agrobiodiversidade nas comunidades guarani...

Os agricultores familiares, os assentados da reforma agrária e os indígenas que multipliquem sementes ou mudas para distribuição, troca ou comercialização entre si ficam isentos da inscrição no Registro Nacional de Sementes e Mudas (Renasem) (Lei 10.711/03, Art. 80, $\left.\S 3^{\circ}\right)$.

O Art. 48 permitiu a inclusão de sementes crioulas em programas de financiamento público da agricultura. Com isso, agricultores que vinham utilizando sementes crioulas/tradicionais passaram a contar com a possibilidade de acessar as linhas oficiais de crédito, como é o caso do Pronaf (Programa Nacional de Fortalecimento da Agricultura Familiar).

O presente trabalho analisa as transformações nas práticas agrícolas a partir dos anos 1950 , os relatos sobre as práticas agrícolas ancestrais e sobre a agrobiodiversidade entre os Guarani-Nhandewa na Terra Indígena Laranjinha, município de Santa Amélia, na região Norte do Paraná. A seção final aborda a experiência das Feiras de Troca de Sementes Crioulas/Tradicionais Indígenas, realizada anualmente na Terra Indígena Pinhalzinho, situada no município de Tomazina (PR), também na região Norte do Paraná, desde 2011 , que é interpretada aqui como uma nova estratégia coletiva para a revalorização e resgate da agrobiodiversidade indígena e não indígena em âmbito regional.

\section{Contexto da Terra Indígena Guarani Laranjinha}

Dados atuais da FUNAI (Fundação Nacional do Índio) revelam que, aproximadamente, 0,25\% da população brasileira é constituída por 225 sociedades indígenas, totalizando 460 mil pessoas. Apesar do histórico de políticas direcionadas à assimilação destes povos à sociedade, as comunidades indígenas no Brasil apresentam expressiva diversidade étnica e linguística. Atualmente, há pelo menos 180 línguas divididas em mais de 30 diferentes famílias linguísticas.

Os índios Guarani pertencem ao tronco linguístico Tupi e à família linguística Tupi-Guarani, sendo subdivididos em três subgrupos que se diferem em suas formas linguísticas, costumes, práticas rituais, 
ALMEIDA, RODRIGUES e NORDER - Agrobiodiversidade nas comunidades guarani...

organização política e social e orientação religiosa: os Mbya, os Nhandewa e os Kaiowa (ALMEIDA e MURA, 2010). Para Schaden (1974), o destaque desta cultura estava na intensa religiosidade, bem como na excelência de sua agricultura, tecelagem e cerâmica. O cultivo do milho e da mandioca tem uma grande importância, ao lado da caça, da pesca e da coleta de produtos florestais.

No território brasileiro, os Guarani totalizam 34 mil pessoas que habitam o Rio Grande do Sul, Santa Catarina, Paraná, São Paulo, Rio de Janeiro e Mato Grosso do Sul (FAUSTINO, 2010). Há comunidades guarani também nos Estados de Espírito Santo, Pará e Tocantins (ISA, 2006). Os Guarani somam 3.055 (de um total de 25.915) indígenas no Estado do Paraná, distribuídos em nove Terras Indígenas, de acordo com o Censo Demográfico de 2010. A TI Laranjinha, situada no município de Santa Amélia, está localizada na porção nordeste do Estado do Paraná, onde vivem cerca de 300 Guarani-Nhandewa, em uma área de apenas 284 hectares demarcados ${ }^{4}$. Há, portanto, uma forte restrição no acesso à terra, uma vez que a disponibilidade de área agrícola é menor do que um hectare para cada habitante desta Terra Indígena. Este processo de "minifundiarização", que representa um obstáculo para a realização de atividades agrícolas e para a melhoria das condições de vida, está associado à reivindicação de territórios ocupados ancestralmente pela etnia na região. Ainda assim, cerca de $30 \%$ da área total da aldeia vem sendo eficientemente manejada nos últimos quinze anos com a finalidade de promover uma restauração da mata nativa (MACIEL, 2012).

A expansão da fronteira agrícola, iniciada a partir da década de 1930, provocou um intenso desmatamento e a abertura de áreas de pastagens e para a agricultura em toda a região norte do Paraná, processo que se intensificou a partir da década de 1970. No interior das terras indígenas da região, tais práticas foram incentivadas pela política integracionista promovida pelo Serviço de Proteção aos Índios (SPI), antigo órgão governamental que tinha como objetivos a pacificação e assimilação dos índios à sociedade brasileira e o seu engajamento no

\footnotetext{
${ }^{4}$ Situada na Bacia do Rio Paranapanema, esta TI tem altitude aproximada de 500 metros e precipitação média anual de $1500 \mathrm{~mm}$. Segundo a classificação de Köeppen (1948), o clima é do tipo Cfa, subtropical úmido (mesotérmico) sem estação seca definida, sendo a Floresta Estacional Semidecidual a sua fitofisionomia predominante.
}

Espaço Ameríndio, Porto Alegre, v. 8, n. 1, p. 40-58, jan./jun. 2014. 
ALMEIDA, RODRIGUES e NORDER - Agrobiodiversidade nas comunidades guarani...

processo produtivo predominante (BORGES e BORGES, 2009).

A agricultura tem sido identificada como a atividade econômica mais importante na comunidade. No entanto, muitas famílias têm buscado ocupação como assalariadas fora da aldeia, com a prestação de serviços temporários e esporádicos em fazendas da região, entre outras atividades de baixa remuneração e demandantes de reduzida qualificação (BARROS, 2003). A TI Laranjinha está atualmente inserida em uma região de agricultura mecanizada voltada para produção de grãos, principalmente milho, soja e, mais recentemente, algodão e cana-de-açúcar. Com isso, a comunidade vem se deparando com uma série de dificuldades ocasionadas, principalmente, pela vinculação a empregos agrícolas temporários e precários (colheita do milho, café e algodão) e, notadamente, pelo insuficiente acesso a áreas agricultáveis (ARAÚjO et al., 2009).

\section{Metodologia da pesquisa}

Para realização da pesquisa, foi utilizada metodologia etnográfica, que busca compreender e descrever a cultura em estudo segundo o ponto de vista dos nativos (SPRADLEY, 1979). Esta abordagem baseia-se na imersão cotidiana nos locais de pesquisa e a partilha de experiências e atividades, coletando dados através de entrevistas, observação e documentos (GENZUK, 2003). Segundo Hammersley (1990), esta metodologia contempla a observação sobre a ação social e a interpretação cultural em seu respectivo contexto. A coleta sistemática de dados é realizada a partir de diversas fontes e não necessariamente de maneira previamente estruturada.

Neste sentido, foi realizada a coleta de dados através de diários de campo, análise de documentos, realização de conversas/entrevistas, visita às áreas familiares de cultivo e produção de fotos e vídeos. As filmagens contemplaram relatos de dezessete indígenas guaraninhandewa: do cacique Márcio Lourenço e seus pais, Dona Lídia Lourenço e Sr. Albani Jacintho; dos seis rezadores mais antigos da TI Laranjinha, Dona Almerinda Norato, Dona Tereza Alves Rodrigues, Sr. Bertolino Rodrigues, Sr. Dercílio da Silva, Dona Rosalina Mira Martins e Sr. 
ALMEIDA, RODRIGUES e NORDER - Agrobiodiversidade nas comunidades guarani...

Benedito Matias; dos ex-moradores da Terra Indígena Laranjinha que atualmente residem no Acampamento Yvyporã, também denominado Posto Velho, Dona Maria Sampaio e Sr. Nelson Agostinho Camargo; dos agricultores indígenas Sr. Irineu Rodrigues, Sr. Júlio da Silva (Sr. Julinho) e Sr. Júlio Portella; Dona Laura Augusta Moraes, indígena da TI Laranjinha que habita a área urbana do município; e do cacique Sebastião Mário Alves e seu filho, Reginaldo Aparecido Alves, pertencentes à TI Pinhalzinho.

Segundo diversos relatos, as variedades de milho indígena Guarani deixaram de ser cultivadas na TI Laranjinha há muitos anos. Apenas dois entrevistados, Dona Lídia e Sr. Julinho, apresentaram exemplares de milho indígena. A primeira mostrou um punhado de sementes de milho guarani, guardado em casa como uma relíquia; o segundo possuía garrafas PET nas quais armazenava algumas sementes de milhos kaingang que recebera havia pouco tempo de um cacique. Neste contexto, a pesquisa voltou-se para a sistematização da memória e do processo histórico que levou a este quadro de perda das variedades de milho indígena e da agrobiodiversidade na TI Laranjinha, bem como sobre as iniciativas voltadas para reinserção da agrobiodiversidade como prática comunitária.

\section{O impacto da agricultura comercial}

Por volta da década de 60, a agricultura tradicional guarani foi se modificando com a intensificação das relações comerciais na agricultura. As colheitas passaram a ser realizadas por cooperativas atuando na região, sendo o milho e o algodão as principais culturas. $O$ cacique Márcio observa que, a partir de 1985, houve uma ampliação da modernização agrícola, tornando os indígenas dependentes da mecanização, do uso de adubos sintéticos, da aplicação de agrotóxicos e do plantio de sementes híbridas. Todo o processo agrícola passou a ser financiado pelas cooperativas, que passaram também a fornecer aos indígenas as sementes e demais insumos necessários para a produção das lavouras comerciais. Deste modo, o uso de agrotóxicos na agricultura foi se disseminando. O trabalho manual, que se ficou 
ALMEIDA, RODRIGUES e NORDER - Agrobiodiversidade nas comunidades guarani...

resumido à capina, foi sendo abandonado, como relata Sr Dercílio: "não precisa nem gastar enxada, fica guardada, é só na base do veneno que o pessoal colhe agora".

Há um descontentamento com a destruição florestal, o assoreamento e a contaminação das águas pelas fazendas no entorno da aldeia e também em relação ao surgimento de "pragas" nas lavouras, fato até então desconhecido. Apesar da reduzida área disponível, os indígenas passaram a adotar o modelo de agricultura predominante em toda a região. A perspectiva de resgatar seus sistemas e práticas tradicionais deixou de ser vislumbrada algo factível a curto e médio prazos. Tal desalento é observado, principalmente, entre os mais idosos, que relatam as técnicas agrícolas tradicionais e seu modo de organização social, e consideram que a juventude deixou de se interessar pela continuidade do saber, interações comunitárias e práticas tradicionais. Este cenário é também interpretado como uma profunda ruptura nas relações sociais, na cultura e nas atividades agrícolas. Os mais velhos dizem estar cansados de dar conselhos aos mais jovens e não serem ouvidos.

Tal ruptura reflete-se fortemente na organização da agricultura, mediante a adoção de sementes de cultivares comerciais e, nos últimos anos, de sementes transgênicas. Além disso, há expressiva redução na diversidade e na quantidade utilizada de sementes tradicionais indígenas. Os exemplares de vegetais de origem indígena cultivados na aldeia tornaram-se desconectados das práticas comunitárias e, em sua maioria, vinham sendo obtidos durante visitas a outras aldeias. Segundo o cacique, as trocas de sementes entre as aldeias não vinham sendo praticadas nos últimos quinze anos, tendo permanecido este intercâmbio restrito a encontros pessoais e visitais esporádicas entre as populações indígenas.

\section{Características da agricultura tradicional}

Segundo os relatos dos anciões, durante o período de suas infâncias, que nos remete às décadas de 1930 e 1950, diversos alimentos eram plantados para o consumo das famílias: "uma miudeza 
ALMEIDA, RODRIGUES e NORDER - Agrobiodiversidade nas comunidades guarani...

de cada coisa", como afirma Sr. Bertolino. Entre as culturas destacavamse arroz, feijão, milho, mandioca e batata doce. Em nenhuma delas eram usados adubos ou venenos, como explica Sr. Dercílio: "era só colocar na terra, nosso adubo é a fé". Naquele período, o povo indígena podia ainda contar com frutas, mel, palmitos, pássaros, caças, tubérculos e muitos outros recursos das matas para alimentação. Havia também a criação de animais, especialmente galinhas, porcos e patos.

Dona Laura, uma das anciãs da comunidade, afirmou que "naquela época, tinha muita fartura; vai ver que por isso que não plantávamos muito". Ela descreve a roça guarani em sua época de criança: "fazia a roçada, um redondo no meio do mato, sempre redondo, e depois fazia o aceiro com enxadão, que é uma vala em volta da roça para evitar do fogo passar para a mata. la queimando tudo e quando chegava no aceiro parava". Na terra com as cinzas era plantado o milho e outras culturas, conforme a preferência da família, predominando feijão, mandioca e abóbora. Enquanto o milho era semeado em toda a área aberta na mata, os demais plantios localizavam-se no espaço mais ao centro. Em geral, neste tradicional sistema de agricultura de coivara, após três colheitas, buscava-se outra área para a realização do roçado.

De acordo com Sr. Nelson, plantava-se com o auxílio de cavadeiras, matracas e do $x o x u$, que podia ser uma madeira qualquer com uma ponta um pouco mais aguda em uma das extremidades. Assim, faziam-se pequenas covas no solo para semear. Outra prática comum utilizada nas áreas de roça era a instalação de armadilhas, uma vez que a fauna era atraída pela disponibilidade de alimentos. Foram relatadas desde armadilhas rústicas confeccionadas com gravetos, folhas e fibras, até o uso de espingardas. Boa parte das atividades de cultivo era realizada por meio de mutirão, realizado a cada dia em benefício de uma família, o que possibilitava a todos os núcleos familiares desfrutar de uma roça a partir de uma vinculação de solidariedade, cooperação e reciprocidade com a comunidade.

Os relatos evidenciam uma satisfação muito grande em relação a esta organização tradicional do trabalho, que contava com refeições oferecidas pelas famílias que estavam recebendo os participantes do mutirão, o que não raro se transformavam em festas no final do dia, com distribuição de bebidas, apresentações musicais e dança. As 
ALMEIDA, RODRIGUES e NORDER - Agrobiodiversidade nas comunidades guarani...

colheitas também se organizavam na forma de mutirões e aconteciam, principalmente, em abril, quando cessavam as chuvas e eram celebradas as festividades do mês indígena. Em tais comemorações, contava-se com a visita de famílias de outras terras indígenas; os pratos típicos eram preparados na aldeia através de uma grande reunião de mulheres, destacando-se uma variada culinária, sobretudo com base no consumo de milho.

As sementes colhidas na lavoura ficavam armazenadas até o próximo plantio e eram abençoadas através de cantos e rezas em uma cerimônia anual. Considerava-se que as sementes rezadas dariam plantas mais fortes e bonitas, além de melhor produção. O uso da fumaça do cachimbo (patynguá) para abençoar as sementes, segundo os entrevistados, era praticado por outras comunidades indígenas, mas não constituía uma prática guarani-nhandewa na região.

Em tempos pretéritos de dificuldades, os rezadores mais fortes "recebiam" sementes de entidades superiores mediante uma conduta bem regrada, repassando-as para que as famílias as plantassem em suas roças. Após passarem alguns dias na casa de reza evitando comidas com sal, açúcar, gordura, frituras e café, os rezadores estavam prontos para executar este mistério. Eles então estendiam um lençol branco onde, ao som de cantos e rezas, depositavam as sementes que caiam com o sacudir do corpo.

Reuniões na casa de reza também eram realizadas em função das condições climáticas. Os indígenas se reuniam para orar a Tupã, Deus do trovão, pedindo uma intercessão pelos cultivos, com o envio de chuvas nas épocas de seca e as controlando em épocas muito úmidas. "Quando chamamos a chuva, ela vem bem antes", relatou Dona Rosa. Após as colheitas, todos se reuniam novamente na casa de reza para agradecer a Tupã e a Nhanderú, Nosso Pai, pela fartura concedida.

Parte do excedente era destinado aos familiares e a indígenas da etnia Kaingang que habitavam as terras do atual Acampamento Yvyporã, na Bacia do Rio Laranjinha, gleba incorporada no processo de revisão da terra indígena5. Naquela época, nada era vendido: "plantava só para o sustento, não se sabia negociar", como narrou Dona Laura. Nos relatos,

\footnotetext{
${ }^{5}$ Cf. Despacho $n^{\circ} 135$, de 30 de Novembro de 2004, da Presidência da Fundação Nacional do Índio, que dispõe sobre a aprovação do Relatório de Revisão de Limites e Delimitação da Terra Indígena Laranjinha.
} 
ALMEIDA, RODRIGUES e NORDER - Agrobiodiversidade nas comunidades guarani...

fica implícita a elevada fertilidade das terras. Dona Lídia sugere que a degradação e a perda das sementes indígenas estejam vinculadas à inserção da aldeia no processo regional de modernização da agricultura: "é por isso que acabou, não era para vender", referindo-se às sementes indígenas.

\section{A memória sobre a agrobiodiversidade}

A memória sobre o milho guarani figura de forma praticamente exclusiva entre os anciões. Foram recordadas as diferentes cores, formatos e características dos grãos e espigas, assim como certos usos e práticas associadas, sendo que o conhecimento culinário foi o mais descrito. Para o plantio, respeitava-se uma distância mínima para que não houvesse cruzamento entre as diferentes variedades. Na coloração dos grãos havia diversos gradientes de amarelo, vermelho, branco e preto, além de variedades de coloração rajada, principalmente de tonalidades claras. Dona Armelinda ressaltou a importância de uma variedade de milho indígena denominada pururuca, caracterizado por ser "pintadinho", com manchas coloridas claras, que era de uso bastante recorrente na comunidade.

A cor da palha também apresentava certa diversidade, havendo variação de tons mais claros ou mais escuros; havia também uma variedade que apresentava a palha na coloração roxa, tradicionalmente muito valorizada para confecção de artesanatos e peças decorativas. Sr. Júlio relata que quanto maior o comprimento da palha, mais apreciada era sua utilização no artesanato. $O$ sabugo também possuía diferentes usos, conforme suas características: dureza, cor e resistência a impactos, podendo ser empregado para formar as brasas do preparo de pães e bolos, na confecção de artesanatos, brinquedos e para higiene pessoal.

Para o preparo dos pratos típicos indígenas eram selecionados os grãos de milho, conforme a maciez e o sabor, provavelmente relacionados com a concentração de amido e outros açúcares presentes em cada variedade. Podem ser citados a paçoca e o virado de banana com farinha de milho como alimentos típicos ainda hoje preparados na 
ALMEIDA, RODRIGUES e NORDER - Agrobiodiversidade nas comunidades guarani...

aldeia, embora a farinha não seja mais produzida localmente com o auxílio do pilão. As variedades de milho pipoca também foram lembradas, tendo sido relatadas como muito apreciadas pelas famílias pelos distintos tamanhos, cores, texturas e maciez. Outros pratos tradicionais, como o cural, o mingau, o milho assado, a canjica e o bolo de milho são pouco encontrados atualmente, diferentemente da abundância e variedade de outros tempos. Segundo Sr. Bertolino, o bolo de milho na cultura guarani-nhandewa era preparado da seguinte maneira:

Antigamente, eu me alembro que eles faziam um fogo no chão e fazia aquela cinza, né? Pegava a massa do milho e ponhava numa caeté. Caeté, sabe o que é, né? É do mato, dá umas folhonas verde. E fazia um forro bem forradinho e despejava a massa dentro daquele coiso e cobria bem cobertinho, e enterrava na cinza quente; cobria bem e deixava lá, deixava cozinhar; ai quando tava bom tirava e era um bolo, um bolo assado na cinza.

Dona Armelinda recorda que o milho ficava de dois a três dias na água para amolecer antes de assar:

Fica molinho! Índio não comia sal! Índio não comia gordura! Comida simples, simples mesmo! Poucos ainda fazem canjica, aquela panelada, igual café, tem uns que adoça com mel, ou com açúcar mesmo, né? Só que tem que cozinhar bem; chega cedo, dá aquela canecada e bebe!.

A canjica, preparada com o milho guarani branco, é tão importante na cultura guarani-nhandewa que foi descrita como oferenda para as entidades espirituais, quando estas desciam ao plano terreno para ajudar os rezadores. Seria este o único prato apreciado pelas divindades quando presentes na Terra, uma vez que possuem alimentos muito melhores de onde vieram.

Além da alimentação, o milho possui propriedades medicinais utilizadas pelo povo guarani-nhandewa. Seu Julinho relata a ingestão do chá das partes femininas do milho, conhecido popularmente como os cabelos da espiga, para o alívio de dores relacionadas ao sistema dos rins e urinário. Segundo o mesmo, o efeito do chá é mais forte quando 
ALMEIDA, RODRIGUES e NORDER - Agrobiodiversidade nas comunidades guarani...

preparado através de uma fervura prolongada.

As sementes de milho para o plantio da safra seguinte eram selecionadas retirando-se as extremidades da espiga, conservando apenas os grãos mais centrais. As sementes ficavam guardadas em cabaças, podendo ser usadas cinzas ou folhas do mato para evitar os carunchos. Segundo os relatos, esta prática permite o armazenamento das sementes de milho por até quatro anos; porém, foi também destacada a importância da renovação, que consiste no plantio anual de todas as sementes armazenadas. Mantém-se, assim, a força vital necessária para a germinação, além da constante adaptação das variedades às características locais.

Contudo, foi relatada uma ocorrência atual muito maior de carunchos nas sementes do milho em comparação com o passado. Este processo, denominado de "enfraquecimento" pelos indígenas, foi relacionado às modificações genéticas e alterações agrícolas estimuladas nas últimas décadas pelos agrônomos ligados às agências governamentais. A confiança na influência das fases da lua para a agricultura também vem se reduzindo: dizem não fazer mais efeito sobre os carunchos. Uma maneira utilizada para o aproveitamento deste milho carunchado é justamente a moagem junto com os grãos sem caruncho e a mistura com toda a farinha resultante como alimento para as criações, sobretudo de galinhas.

Vale acrescentar que no entorno da casa das famílias dos rezadores ainda hoje são encontradas algumas plantas utilizadas em rituais religiosos, como o porungo (Lagenaria sp.), denominado pelos Nhandewa como yakuá, presente no altar do Mongaraí, ritual de batismo guarani, repleto de água com pétalas de flores. Outro vegetal típico da cultura guarani, o cipó imbé ou guaimbé (Philodendrum sp.), também é encontrado nos arredores das casas, sendo utilizado como uma fonte de fibras para artesanato e confecção de artigos religiosos, além do consumo de seu fruto, também bastante apreciado.

\section{As Feiras de Trocas de Sementes Crioulas/Tradicionais Indígenas}

Em 27 de agosto de 2011, foi realizada na TI Pinhalzinho a / Feira 
ALMEIDA, RODRIGUES e NORDER - Agrobiodiversidade nas comunidades guarani...

de Troca de Sementes Crioulas/Tradicionais Indígenas, que segundo os próprios indígenas constituiu a primeira iniciativa organizada formalmente por uma rede de atores sociais no interior de uma aldeia indígena na região sul do Brasil. A iniciativa partiu das lideranças da comunidade guarani-nhandewa da TI Pinhalzinho, localizada no município de Tomazina/PR, a cerca de $70 \mathrm{~km}$ da TI Laranjinha. A motivação surgiu justamente do interesse pela revalorização das sementes tradicionais guarani para as roças das famílias, como nos relata Reginaldo, filho do cacique Sebastião e uma das lideranças do atual movimento indígena: "a preocupação é manter o costume, manter a cultura. Tínhamos perdido todas as sementes indígenas". O atual levantamento da sociobiodiversidade presente na TI Pinhalzinho, apresentado por Dremiski (2011), evidencia a escassez de sementes tradicionais na aldeia, o que aponta para a importância das iniciativas visando estimular a revalorização e resgate deste material genético.

As parcerias com o Instituto Federal de Educação, Ciência e Tecnologia do Paraná (IFPR), coordenação da FUNAI e SESI viabilizaram a realização da / Feira, tendo sido articulada também com movimentos sociais, como o Movimento dos Trabalhadores Rurais Sem-Terra (MST), universidades da região e organizações não governamentais. Apenas indígenas kaingang da TI São Jerônimo e guarani da TI Queimadas puderam participar do evento, pois foram apenas estas duas comunidades que obtiveram apoio das prefeituras para viabilizar o transporte até a TI Pinhalzinho.

A maioria dos indígenas participantes da feira era composta por estudantes e jovens, parte dos quais com algum engajamento no movimento agroecológico. O grupo proveniente da TI Queimadas trouxe sementes de milho guarani da palha roxa e do grão pintado, que continuam sendo cultivados em seu território, no litoral paranaense, onde conseguem manter um conjunto de práticas agrícolas tradicionais.

$\mathrm{Na}$ abertura do evento, houve a apresentação do grupo de canto da TI Pinhalzinho; em seguida, um teatro realizado pelos indígenas questionava os conflitos gerados pela posse da terra e a construção de hidrelétricas. Foram organizadas palestras de agricultores que levaram suas sementes crioulas. Foram abordadas, no período da manhã, as técnicas de manejo e apresentadas sugestões para propagação das 
ALMEIDA, RODRIGUES e NORDER - Agrobiodiversidade nas comunidades guarani...

sementes. Durante a tarde, aconteceram oficinas sobre plantas medicinais, confecção de vassouras, artesanato e armadilhas, esta última exclusiva para as crianças e jovens da escola.

As sementes trazidas para a / Feira de Troca de Sementes Crioulas/Tradicionais Indígenas foram abençoadas pelo tchamoi, sábio e rezador da cultura guarani, através de cantos e reza. Após o ritual, as famílias puderam escolher e trocar as sementes de seu interesse, levando-as para o plantio em suas roças. Reginaldo comenta que "ainda falta, mas a maioria conseguiu resgatar. Agora é produzir para não perder!". O total, neste único dia de Feira, foi de 300 participantes, sendo que aproximadamente $40 \%$ eram moradores da TI Pinhalzinho, além de alguns moradores da aldeia que apenas colaboraram com seus preparativos.

Reginaldo estima um favorável resultado desta atividade entre os participantes que receberam as sementes durante a / Feira, o que vem contribuindo para a reprodução das sementes: "Pinhalzinho ficou um bom tempo sem plantar nada. A turma desanimou, não tinha incentivo. A Feira animou para plantarem em seus quintais as sementes tradicionais". Tendo em vista o alcance desta iniciativa, diversas parcerias foram realizadas com a finalidade de realizar a // Feira de Trocas de Sementes na Terra Indígena Pinhalzinho em agosto de 2012, época do ano propícia para que as famílias e os estudantes voltem para suas roças com as sementes trocadas e reiniciem os plantios para a primavera.

Diante deste cenário de reconstrução das práticas sociais para a manutenção da agrobiodiversidade, foi organizada a III Feira de Trocas de Sementes, também em Tomazina (PR), em agosto de 2013 e que já se inscreve em um histórico recente e altamente relevante de reconstrução das práticas coletivas para a manutenção da agrobiodiversidade entre as comunidades indígenas e camponesas na região Norte do Paraná.

\section{$O$ resgate da agrobiodiversidade}

Todos os entrevistados mostraram interesse em resgatar a 
ALMEIDA, RODRIGUES e NORDER - Agrobiodiversidade nas comunidades guarani...

agrobiodiversidade guarani. A possibilidade de voltar a ter acesso a este patrimônio genético através das sementes disseminadas pelas Feiras de Troca de Sementes Crioulas/Tradicionais Indígenas realizadas na TI Pinhalzinho, diante das novas interações e perspectivas, representa um novo alento para indígenas guarani-nhandewa da $\mathrm{TI}$ Laranjinha. Segundo Dremiski (2011), a renovação na organização das comunidades indígenas e suas instituições têm grande importância para a preservação das sementes tradicionais, sendo a que as Feiras de Troca de Sementes representam uma renovada base para o desenvolvimento de processos locais de proteção comunitária da agrobiodiversidade.

Segundo Felipim (2001), a conservação in situ das variedades do milho tradicional guarani depende de duas condições fundamentais: o caráter sagrado atribuído ao milho pela religiosidade guarani e a existência de aldeias em ambientes naturais ainda conservados e favoráveis ao manejo e à manutenção das diversidades dos cultivares agrícolas, que funcionam como bancos de germoplasma. A experiência da aldeia guarani-mbya da llha do Cardoso evidencia a importância estratégica destas famílias para a manutenção do patrimônio genético indígena e como matriz para o fornecimento de sementes para outras aldeias, como almeja, entre outras, a comunidade da TI Laranjinha.

Para o cacique Márcio, é muito importante que estas sementes sejam recuperadas. Ele citou a necessidade de mostrar algo palpável para seus filhos, além de reproduzir os relatos de como era no passado. Além disso, afirma que o resgate das variedades de milho impulsionará o resgate de outras práticas e costumes do universo indígena para as gerações mais novas, além de toda riqueza da agrobiodiversidade manejada pelos ancestrais.

Em determinada ocasião, o cacique recebeu da EMATER (Empresa de Assistência Técnica e Extensão Rural) uma pequena quantia de sementes amarelas, vermelhas e roxas de milho indígena dos Kaingang; considera ter se equivocado ao distribuir os poucos grãos obtidos entre as famílias, pois sendo ínfima a quantidade disponibilizada, não houve sua reprodução ao longo do tempo.

Vem sendo considerada na comunidade Laranjinha a possibilidade de obtenção de variedades de milho indígena junto a outras terras indígenas, povos e comunidades tradicionais, universidades, grupos de 
ALMEIDA, RODRIGUES e NORDER - Agrobiodiversidade nas comunidades guarani...

Agroecologia, organizações governamentais e não governamentais e agências de ATER. Durante a realização da pesquisa também foi construída uma proposta, baseando-se nas experiências pretéritas de perda das sementes pelas famílias da TI Laranjinha, de estabelecimento de campos de cultivos para geração de sementes, e esta vem recebendo a atenção e apoio das lideranças.

Vislumbra-se que, na medida em que as sementes forem sendo encontradas, ocorra o cultivo primeiramente como um "campo de sementes", principalmente no caso de haver reduzida disponibilidade, para em um segundo momento distribuir as sementes produzidas entre as famílias que desejarem plantar o milho e outros alimentos com sementes tradicionais. A aplicabilidade torna-se ainda maior para o caso da TI Laranjinha, pois este sistema de plantio, voltado para geração de sementes, exige uma pequena área para o cultivo.

Outro aspecto favorável dos campos de sementes está no melhoramento participativo das variedades cultivadas, o que pode contribuir para ampliar um conjunto de experiências com milho crioulo no Estado do Paraná (MALDONADO et al., 2006). Através da seleção de sementes com características de maior interesse comunitário, o que já era realizado pelos Guarani-Nhandewa, a comunidade da TI Laranjinha tem a possibilidade de melhorar a adaptação das variedades indígenas às condições ambientais locais e resgatar as qualidades de cada cultivo conforme suas demandas.

\section{Conclusões}

O presente trabalho, além de registrar aspectos do conhecimento guarani sobre a agricultura tradicional, ressaltou as motivações da comunidade da $\mathrm{TI}$ Laranjinha para iniciar o resgate da agrobiodiversidade, focando especialmente as variedades de milho. $O$ resgate do controle comunitário sobre as sementes tradicionais contribui para a reconstituição da identidade social, fortalece e revaloriza as práticas culturais e promove o empoderamento das comunidades na busca de maior autonomia.

As Feiras de Trocas de Sementes Tradicionais/Crioulas Indígenas, 
ALMEIDA, RODRIGUES e NORDER - Agrobiodiversidade nas comunidades guarani...

realizadas anualmente a partir de 2011 , na Terra Indígena Pinhalzinho, município de Tomazina (PR), vêm reunindo um número crescente e diversificado de indígenas, camponeses e instituições; e representam uma nova estratégia coletiva voltada para a preservação da agrobiodiversidade junto às comunidades Guarani e Kaingang, bem como de agricultores camponeses da região Norte do Paraná.

Há uma retomada do debate político local e regional sobre a importância das sementes tradicionais dos povos indígenas e a busca por novas práticas, entre as quais, o estabelecimento de campos de sementes tradicionais, indígenas e crioulas. Com isso, evidencia-se um processo recente e renovado de organização política voltado para a reconstrução social e cultural da agrobiodiversidade entre as comunidades indígenas na porção norte da região Sul do Brasil.

\section{Agradecimentos}

Gratidão a todos os povos indígenas, especialmente os Guarani Nhandewa da TI Laranjinha e TI Pinhalzinho; à ARPIN-SUL (Articulação dos Povos Indígenas - região Sul) e à Universidade Federal de São Carlos, campus de Araras, assim como a todas as pessoas que generosamente doaram seu tempo e conhecimento para que esta pesquisa fosse realizada.

\section{Referências bibliográficas}

ALMEIDA, Rubem Ferreira Thomaz; MURA, Fábio. Guarani Nãndeva. In: INSTITUTO SOCIOAMBIENTAL. Povos Indígenas no Brasil. São Paulo: ISA, 2003. Disponível em: http://pib.socioambiental.org/pt/povo/guarani-nandeva . Acesso em: 26 jun. 2014.

ARAÚJO, Rita de Cássia de et al. Memórias, conhecimentos e literatura na escola indígena Guarani Nhandewa. In: IX Congresso Nacional de Educação; III Encontro Sul Brasileiro de Psicopedagogia, Curitiba. Anais... Curitiba, 2009, p. 9404 - 9413.

BARROS, Valéria Esteves Nascimento. Da casa de rezas à Congregação Cristã no Brasil: o pentecostalismo guarani na Terra Indígena Laranjinha/PR. 2003. $119 \mathrm{f}$. 
ALMEIDA, RODRIGUES e NORDER - Agrobiodiversidade nas comunidades guarani...

Dissertação (Mestrado em Antropologia Social) - PPGAS, UFSC, Florianópolis, SC, [2003].

BORGES, Paulo Humberto Porto; BORGES, Liliam Faria Porto. A educação escolar integracionista e a representação fotográfica. Revista Latinoamericana de Tecnología Educativa, Cáceres, v. 8, n. 2, p. 77-90, 2009.

CAPORAL, Francisco Roberto; COSTABEBER, José Antonio. Agroecologia: enfoque científico e estratégico para apoiar o desenvolvimento rural sustentável. Porto Alegre: EMATER/RS, 2002.

CASCUDO, Luís da Câmara. Dicionário do folclore brasileiro. Rio de Janeiro: Ediouro, 1959.

DREMISKI, João Luis. Proteção das sementes crioulas indígenas como direito humano. 2011. 169 f. Dissertação (Mestrado em Direito) - PPGD, PUC-PR, Curitiba, PR, [2011].

FAUSTINO, Rosângela Célia. Religião Guarani Nhandewa: uma complexa organização e recriação para a vida e a educação. Revista Brasileira de História das Religiões, Maringá, v. 3, n. 7, p. 47-71, mai 2010.

FELIPIM, Adriana Perez. O sistema agrícola Guarani Mbyá e seus cultivares de milho: um estudo de caso na Aldeia Guarani da Ilha do Cardoso, município de Cananéia, SP. 2001. 120 f. Dissertação (Mestrado em Ciências Florestais) - Esalq, USP, Piracicaba, SP, [2001].

GENZUK, Michael. A Synthesis of Ethnographic Research. Los Angeles: Center for Multilingual/University of Southern California, 2003.

HAMMERSLEY, Martyn. Reading Ethnographic Research: a critical guide. London: Longman, 1990.

INSTITUTO SOCIOAMBIENTAL. Quadro geral dos povos indígenas no Brasil. In: . (Org.), Povos Indígenas no Brasil. São Paulo: ISA, 2006. Disponível em: http://pib.socioambiental.org/pt/c/quadro-geral . Acesso em: 26 jun. 2014.

KÖEPPEN, W. Climatologia: con um estúdio de los climas de la Tierra. México: Fondo de Cultura Economica, 1948.

MALDONADO, Josué et al. Fitomejoramiento participativo de variedades de maíz criollo: uma experiencia en la región centro sur de Paraná, Brasil. In: RÍOS, H., HERNÁNDEZ, M. M.; ROSAS, C. (Org.). Fitomejoramiento participativo: los agricultores mejoran cultivos. La Habana: INCA, 2006. p. 197-219.

PLOEG, Jan D. Sete teses sobre a agricultura camponesa. In: PETERSEN, Paulo (Org.). Agricultura familiar camponesa na construção do futuro. Rio de Janeiro: ASPTA, 2009. p. 17-31. 
ALMEIDA, RODRIGUES e NORDER - Agrobiodiversidade nas comunidades guarani...

MACIEL, Vitor Renck. Restauração florestal em áreas de pastagem na Terra Indígena Laranjinha, Santa Amélia/PR. 2012. 100 f. Dissertação (Mestrado em Agroecologia e Desenvolvimento Rural) - PPGADR, UFSCar, São Carlos, SP, [2012].

SANTILLI, Juliana. Agrobiodiversidade e direitos dos agricultores. São Paulo: Peirópolis, 2009.

SCHADEN, Egon. Aspectos fundamentais da cultura Guarani. São Paulo: EPU/Edusp, 1974.

SPRADLEY, James. The Ethnographic Interview. New York: Holt, Rinehart and Winston, 1979. 